\title{
Caste and Identity Processes among British Sikhs in the Midlands
}

\author{
Rusi Jaspal \\ De Montfort University Leicester \\ Opinderjit Kaur Takhar \\ University of Wolverhampton
}

\begin{abstract}
This article examines the role of caste in the lives and identities of a small sample of young Sikhs in the English Midlands, using social psychological theory. In many academic writings, there is an implicit representation of caste as a negative aspect of South Asian culture and religion, and of caste identification as a means of oppressing vulnerable outgroups. Twentythree young Sikhs were interviewed, and the qualitative data were analysed using Identity Process Theory. The following themes are discussed: (i) Caste as a Dormant Social Category, (ii) Anchoring the Caste Ingroup to Positive Social Representations, and (iii) Caste as an Inherent or Constructed Aspect of Identity? It is argued that neither caste nor castebased prejudice appear to be prominent in the lives and identities of our interviewees but that, because caste is an important symbolic aspect of identity which can acquire salient in particular contexts, some Sikhs may wish to maintain this identity though endogamy. What is understood as caste-based prejudice can be better understood in terms of the downward comparison principle in social psychology. The implications for caste legislation are discussed.
\end{abstract}

\section{INTRODUCTION}

South Asian communities in both the Subcontinent and the diaspora continue to adhere to long-standing traditions, conceptions and associations based on caste. Many Dalit ${ }^{1}$, Hindu and Sikh surnames are caste-based, which can render caste identities identifiable on the basis of one's surname. ${ }^{2}$ The Tat Khalsa ideal was to discontinue the use of caste names in favour of Singh and Kaur, which was viewed as a means of putting an end to caste-based prejudice among Sikhs. However, there is evidence that caste remains a phenomenologically important identity among many Sikhs and that, despite theological attempts to distance Sikhism from the institution of caste, many Sikhs continue to view this as an important cultural component of identity. Caste identity continues to play a role in individuals' decision-making and judgements about others' social status, character and competence, and caste-based stereotypes are often salient, even among those individuals who deny attributing importance to caste (Jaspal, 2011).

In the last decade, organisations such as CasteWatchUK and the Anti Caste Discrimination Alliance (ACDA), representing a number of community groups mostly identified with Dalits, have been actively engaged in raising public awareness of caste-based discrimination in the UK. Such organisations have been campaigning to raise awareness of the notion that caste discrimination is embedded within the psyche, and thus practices, of South Asians (predominantly Hindus and Sikhs) resident in the UK. Supporters of the campaign strongly argued that equality legislation must be amended in order for caste-based discrimination to be recognised as unlawful on British soil. On 23 April 2013, Parliament agreed an amendment on caste to the Enterprise and Regulatory Reform Bill. However, there has been considerable opposition to anti-caste legislation from a number of Hindu and Sikh organisations in the UK, who argue that caste-based prejudice is rapidly disappearing and that any requirement for people to record their caste would, ironically, embed and institutionalise 
caste-based divisions in British society and create tensions between caste groups. The British Sikh Report $2013^{3}$, for example, indicates that a majority $(61.2 \%)$ of the 662 British Sikhs who responded to a questionnaire indicated that they have no concern for caste-related issues.

In a qualitative interview study using IPT, we set out to examine the role of caste in the lives and identities of a small sample of young Sikhs in the English Midlands, using social psychological theory. More specifically, the study focuses on (i) the importance appended to caste identity among our interviewees, (ii) how one's caste membership (and indeed, knowledge of others' caste membership) may shape the identity principles, and (iii) how young Sikhs may cope with real or potential cases of identity threat associated with caste.

\section{Anti-Caste Legislation: The Opponents and Supporters}

Supporters of the anti-caste legislation have argued, largely on the basis of their own experiences and knowledge, that there is ample evidence of the existence of both individual and institutional forms of caste discrimination amongst South Asians in Britain (see Takhar 2011). However, there is in fact little empirical evidence concerning caste-based discrimination, which renders it difficult to assess the necessity of anti-caste legislation. Few quantitative or qualitative empirical studies of caste identity and caste ingroup relations have been conducted in the UK context. Anecdotally at least, religious establishments have often been reported as the prime context for caste-based discrimination. ${ }^{4}$ The words of Omprakash Valmiki in his autobiography, Joothan (2003), are pertinent when analysing Dalit activism in support of the legislation:

"Dalit life is excruciatingly painful, charred by experiences. Experiences that did not manage to find room in literary creations. We have grown up in a social order that is extremely cruel and inhuman. And compassionless towards dalits" (p. xiii).

This quote is valuable in understanding the perspective of activism in support of anti-caste legislation - caste is represented as a negative aspect of South Asian culture and religion, and caste identification as a means of oppressing vulnerable outgroups. However, there is generally little understanding of the social psychological roles and functions performed by caste identification (though see Ballard, 1994, for insights into the cultural aspects of caste).

Opponents of the anti-caste discrimination legislation identify a number of concerns in relation to the introduction of such legislation in the UK. For instance, it has been noted that the National Institute of Economic and Social Research (NIESR) report indicated that it had found evidence for caste based discrimination in Britain by documenting thirty case studies. The perpetrators of the discrimination, according to the report, were entirely from the Hindu and Sikh community. The findings of the report were dismissed by Sikh and Hindu national organisations as being flawed due to the small and non-representative sample, which they felt rendered the results non-generalisable to the British South Asian population. Hindu and Sikh organisations argued, and continue to argue, that legislation against caste-based discrimination is an ill-conceived and unnecessary form of activism by Dalit organisations, since in their opinion the NIESR approach was extremely biased towards the Dalit community. According to opponents, the report does not provide a true reflection of how British South Asians habitually think about caste. The opponents have consistently pointed to the fact that the thirty case studies take into account entirely the testimonies of individuals from the Dalit communities and that the option for Hindus and Sikhs to offer informant testimonies has been ignored in the gathering of qualitative data by the NIESR researchers. Moreover, it is argued that most British South Asians do not append importance to caste or engage in caste discrimination. There is, thus, an assumption that caste simply does not 
matter. Sikh and Hindu groups opposed to the anti-caste legislation are adamant that the legislation could make things worse by re-inscribing caste-based identities that have diminishing currency, especially for young people. This study aims to examine the social and psychological significance of caste for young Sikhs, which would begin to shed light on the necessity and functionality of anti-caste legislation in the UK.

\section{Social Sciences Approaches to Caste}

There has been a fair amount of sociological and anthropological research into caste in both the Indian Subcontinent and the South Asian diaspora. Caste prejudice and discrimination in the Indian context have persisted despite the many reform movements that have spoken out against its discriminatory element and the anti-caste legislation that has been promulgated in India (Takhar 2005; Kalsi 1989). Moreover, the founding principles of the Sikh faith concerned the rejection of caste-based notions of superiority and inferiority of individuals. Several writers have indicated that caste is the principal institution that governs social and personal relationships in the Subcontinent (Dumont, 1988; Gupta, 2004). Due to its longstanding cultural and religious significance in various spheres of life in the Subcontinent, caste remains significant for many people across a multitude of social domains (Judge \& Bal, 2008). This is of course partly maintained by the historical significance of caste, the cultural and spatial reflections of caste, and the construction of other religious and political identities on the basis of caste identities (e.g. the emergence of Ravidassia, Valmiki, Ad Dharm identities) (Takhar, 2014; Kalsi, 1989), given that these "new" identities too serve to reify and perpetuate the caste system, albeit in indirect ways (see Ram 2008 \& Takhar 2011).

There are many accounts of caste-based prejudice in the Subcontinent. Jodhka (2004) describes a case of conflict between Jats and the Scheduled Castes over the administration of a Sikh temple - the Sikh minority of the village essentially refused to allow the Scheduled Caste majority to be involved in its administration. Pawar (1993) notes the tendency for Jats and other privileged caste groups to block access to communal facilitates, such as places of worship, to members of the Scheduled Castes in Indian village contexts. Jeffrey (2001) has highlighted the submissiveness of the Scheduled Castes in face of intimidation from the dominant Jat majority. Moreover, there appears to be an essential understanding of caste, that is, as an immutable, quasi-biological "trait" that cannot be relinquished (Jaspal, 2011; Mahalingham, 2007). This can serve to perpetuate negative caste intergroup relations, as well as resistance to social change that challenges the status quo.

In their work on caste in the Subcontinent, Gorringe and Rafanell (2007) highlight three key dimensions of caste, namely (i) social hierarchy, (ii) endogamous separation, and (iii) the interdependent division of village, which shape caste identity and relations within village contexts. In the South Asian diaspora, however, only the first two dimensions appear to be active in shaping caste identity - many Sikhs do continue to perceive caste in terms of a social hierarchy, which can be maintained only through strict endogamy (Takhar, 2005). Indeed, Chowdhry (2004) notes that difference and hierarchy are two key underlying principles of the caste system, which are supported by endogamy. However, it must be noted that even in the South Asian diaspora, Scheduled Caste groups such as the Valmikis can face social disparagement from historically privileged caste groups who continue to associate the Scheduled Castes with demeaning occupations and practices (Nesbitt, 1994; Takhar, 2014). The largely sociological and anthropological accounts of caste identity in the South Asian diaspora tend not to examine the motivations and functions that caste identity performs at both social and individual levels (cf. Jaspal, 2011). We believe that a qualitative social psychological approach to examining caste identity can shed light, firstly, on the importance appended to caste among young Sikhs (and indeed among other South Asian groups) and, 
secondly, why they identify with caste and the role that caste identification plays in intergroup relations.

\section{Caste and Identity: A Social Psychological Framework}

Identity Process Theory (IPT) (Breakwell, 1986; Jaspal \& Breakwell, 2014) is a social psychological theory of identity construction, threat and coping. It explicitly focuses on how the individual engages with the social world (including with social-level phenomena, such as the caste system) in order to protect identity at an individual level. IPT postulates that two psychological processes underlie identity construction: assimilation-accommodation and evaluation. The assimilation-accommodation process serves to draw new information into one's sense of self, while the evaluation process enables to the individual to confer meaning and value on new and existing information. For instance, a young Sikh may discover from his family that being a Jat is important and that he should associate with other Jat individuals (assimilation-accommodation), and this group membership may come to represent a meaningful and important aspect of identity (evaluation).

According to IPT, the two identity processes function to create "desirable end-states" for identity, which are referred to as identity principles. These include: (i) continuity; (ii) distinctiveness; (iii) self-efficacy; and (iv) self-esteem. Clearly, some of the new information that the individual encounters will enhance these principles, that is, provide high levels of self-esteem, distinctiveness and so on. For instance, the discovery that one's caste ingroup has historically been associated with the inception of Sikhism may well provide members of that caste group with feelings of self-esteem. Conversely, some new information can easily frustrate one of more of these principles. For instance, exposure to caste-based prejudice from caste outgroups can deprive individuals of self-esteem and self-efficacy. The theory postulates that if the identity principles are, for whatever reason, frustrated, the processes will be unable to function satisfactorily, which will result in threats to identity. In response to identity threat, the individual will engage in coping strategies in order to restore and maintain appropriate levels of the principles. Identity threat is aversive for psychological wellbeing and, thus, individuals do their utmost to avert it.

Jaspal (2011) has argued that IPT can explain the persistence and functionality of caste in both the Subcontinent and in the South Asian diaspora. One's caste group membership can clearly provide feelings of continuity given its long-standing nature, selfesteem when it is socially represented in positive terms, self-efficacy if the group membership is perceived as empowering its members, and distinctiveness given its focus on the historical uniqueness of each caste group. Similarly, caste can frustrate the identity principles, particularly when it is employed to disparage others (self-esteem), to limit one's abilities (self-efficacy), or to categorise individuals in inaccurate ways (distinctiveness). However, Jaspal (2011) does hypothesise that caste, and indeed the caste system more generally, may persist given its long-standing nature and its historical underpinnings - that is, people may resist dismantlement of the caste system because of its contribution to continuity. Accordingly, in this article, IPT is employed as a guiding framework for understanding young Sikhs' accounts of caste identification.

\section{Participants and procedure}

\section{METHOD}

A snowball sampling strategy was employed in order to recruit participants for this study, and participants were recruited from within the first author's social network. Twenty-three selfidentified British Sikh men and women were recruited from the South Asian community in 
the English Midlands. Participants were aged between 18 and 25 years (M: 23), and 14 were male and 9 were female. The study was limited to young Sikhs because we were interested in exploring how young Sikhs manage the tension between official resistance to caste in Sikh theology and the cultural adherence to caste among many Sikhs (Takhar, 2005). All participants defined themselves as being either "moderately religious" or "very religious" Sikhs. Participants were asked to indicate their caste group identity. Ten individuals selfidentified as Jat, seven as Saini and six as Dalit. ${ }^{5}$

The participants, regardless of caste background, were interviewed using the same semi-structured interview schedule consisting of twelve exploratory, open-ended questions regarding: self-description, self-categorization and identity (based on IPT), caste background, relations with members of their caste ingroup and outgroups, and potential experiences of caste discrimination (as perpetrator and victim). Interviews lasted between 60 and 90 minutes, and were recorded and transcribed verbatim. The research was conducted in accordance with British Psychological Society ethical guidelines and pseudonyms are used in order to protect participant anonymity.

\section{Analytical approach}

Interpretative Phenomenological Analysis (IPA) (Smith \& Osborn, 2008) is a qualitative analytical technique that aims to capture participants' attempts to make sense of their personal and social worlds. The approach assumes a relationship between verbal reports and the cognitions and emotions with which they are concerned (Smith \& Osborn, 2008). Since the method focuses upon the meanings that particular lived experiences hold for the individual, it was anticipated that this analytical strategy would shed light upon the subjective perceptual processes associated with participants' attempts to make sense of their caste identity. Moreover, the method's idiographic mode of enquiry facilitates in-depth exploration of each individual's account of their experiences.

The authors transcribed the recordings and read the transcripts repeatedly in order to become intimate with the accounts, and preliminary interpretations were noted in the left margin. These included inter alia participants' meaning-making, particular forms of language, and apparent contradictions and patterns within the data. Initial codes aimed to capture, from the analyst's perspective, participants' attempts to make sense of their identities and experiences. At the next step, the right margin was used to collate these initial codes into potential themes, which captured the essential qualities of the accounts. The list of themes was reviewed and interview extracts were listed against each corresponding theme. Superordinate themes were developed and ordered into a logical and coherent narrative structure. Due to space constraints, extracts are presented only to exemplify major substantive and theoretical points which are illustrative of the dataset as a whole.

\section{ANALYSIS}

This section outlines and discusses the following themes: (i) Caste as a Dormant Social Category, (ii) Anchoring the Caste Ingroup to Positive Social Representations, and (iii) Caste as an Inherent or Constructed Aspect of Identity?

\section{Caste as a Dormant Social Category}

There is evidence that caste constitutes an important component of identity among South Asians, both in the Indian Subcontinent and in the diaspora (Ballard, 1994; Gupta, 2004). However, for our interviewees, caste generally did not appear to be a salient aspect of identity: 
It's not as if caste is ever on my mind. I don't exactly wake up thinking "oh, I'm a Jat, how wonderful" (laughs). It is something, I know, but something that's not on my mind much (Satinder, Jat)

I'm not that bothered about it, if I'm honest [...] to me, being a Sikh is more important. I don't really ask someone what caste they are, or care really (Amandeep, Saini)

Respondents did not attribute importance to caste, although they acknowledged that it constituted an aspect of their identities. This was not salient at a psychological level, given that individuals reportedly did not think about this group membership, or at a social level, as this did not necessarily shape quotidian interactions with other people. Like Amandeep, interviewees tended to point to other more superordinate group memberships, such as their Indian ethnic identity or their Sikh religious identity, in defining themselves and as factors that shaped their interactions with others. In short, other identities appeared to be more salient than caste.

Like respondents of the Jat and Saini caste groups, for whom caste was not salient, Dalit individuals expressed little knowledge of their caste background:

Caste is not a big thing in my life really. I don't really care much. It's more an India-related thing isn't it? [...] I'm Indian in origins but we're not into caste and that (Kamaljit, Dalit)

Other than a few times at school, like childish fighting, I've never been a victim of abuse or anything because I'm a Dalit [..] I don't know what people privately think but it's not really been shown or anything (Amanjit, Dalit)

Kamaljit attributed caste to dominant Indian culture (in the Subcontinent) and distanced it from British Asian/Indian identity. It is noteworthy that most Dalit participants attributed importance to superordinate identities, like Indian ethnic identity, as Kamaljit did. However, there was a differentiation between Indian ethnicity in the Subcontinent and in the diaspora, respectively. Caste was perceived largely as a non-issue in the diaspora - most Dalit interviewees reported no experiences of overt discrimination on the basis of their caste background, which suggested that this was not salient in interpersonal relations between British Sikhs. Amanjit did recognise that his caste background had infrequently been flagged up in the school environment in "childish fighting", but none of the respondents appended significance to these experiences. The overarching consensus among Dalit interviewees was that caste discrimination was insignificant in their lives.

However, there was some social contexts in which caste identity reportedly did acquire salience for all caste groups, namely in interactions with first-generation South Asians:

We don't ask that at school or college or anywhere. I remember my best friend came and it's my mum who was like "oh di jaat ki eh?" [what's his caste?] and I didn't know. I had to ask (Gurjit, Saini)

Caste, for me, has only been an issue when I've thought "I've got a girlfriend. I've got to introduce her to my parents and family." I knew they'd think something of it. I never bothered. It turned out she was a Saini so not a big deal for them. (Manjit, Jatt)

I reckon my parents would prefer it if I got married in our own caste [...] it's about, do we fit together or not? So there's always that preference (Sartaj, Dalit) 
Gurjit reiterated the point that caste identity was latent in most social context, such as in educational and vocational settings, and that, consequently, this did not impinge upon interpersonal relations. Caste only acquired salience in the familial context because his mother reportedly enquired about the caste background of his best friend. Gurjit's best friend's caste background was important to his mother, possibly because caste is often employed as a means of judging the character and morality of an individual (Dhanda, 2009). However, Gurjit had himself never enquired about his best friend's caste background. Although young British Sikhs themselves may be largely indifferent to caste, many recognise that their parents and elders (the first-generation) do attribute importance to caste, particularly in the context of marriage. Manjit himself was not particularly concerned about caste but understood the social obligation to ascertain his girlfriend's caste background in order to gain the acceptance and endorsement of his parents.

Respondents were aware that their elders might oppose familial union with particular caste groups (perceived as being "low" caste groups). In Manjit's case, his parents believed that a Saini caste group member could be a suitable partner for their son. Dalit interviewees also indicated that their elders appended significance to caste in the context of marriage. Given that marriage is considered a union not only between two individuals but also between their respective families, there was reportedly a "preference" among Dalit families that their children marry within their own caste group. In short, there was a general expectation of caste endogamy among first-generation South Asians of all three caste backgrounds. This essentially highlighted the underlying desire for all three caste groups to maintain a sense of intergroup distinctiveness and to preserve their caste group identity, which of course are important principles of identity in IPT. The central point is that, despite the general indifference to caste in daily life, caste appeared to acquire salience in specific social contexts, such as in interactions with elders (for whom caste was of greater importance) and in the context of marriage.

\section{Anchoring Caste to Positive Social Representations}

Although caste identity was not particularly salient in people's everyday lives, when respondents were invited to reflect upon the value of their caste identities, they tended to construct the caste ingroup in positive terms. Individuals engaged in the evaluation process of identity construction by appending positive meaning and value to their caste identities - there was an anchoring of their caste identity to positive representations:

We Jats are the most important caste in Punjab. I mean, it's like the proper Sikh caste, isn't it? Jats do the bhangra music that everyone listens to and, you know, there's a lot of pride that we have. It's a traditional thing. (Jas, Jat)

Yeah, when you do think about it, Jats are a good caste because we are the ones who give work to people in the village and own land and the Jats have pride. We are a proud "zaat" [caste]. You look at our weddings and see what it's like. (Sukhi, Jat)

Individuals who identified with the Jat caste expressed particular pride their caste group membership, often drawing upon cultural representations of Jats in doing so (Sato, 2012). For instance, Jas highlighted the position of Jats in bhangra music, which is of course a popular genre of music among British South Asians. Moreover, he accentuated the significance of the Jat caste in the Indian state of Punjab as well as in the Sikh faith. The notion of authenticity was appended to the Jat caste as "the proper Sikh caste", thereby attributing to the Jats the most important position within the Sikh faith. The perception of the Jas caste as an 
"authentically" Sikh one provided feelings of distinctiveness from caste outgroups who were, implicitly, regarded as less authentically Sikh. Moreover, in reflecting upon the significance of his caste identity, Sukhi referred to Jats as "a good caste" that makes positive contributions to the Punjabi villages in which they reside. More specifically, she referred to the historical caste-based division of labour in the Indian Subcontinent, which attributed to the Jats a position of power as landowners (Jodhka, 2004). Sukhi and other Jats invoked the Jat role in providing jobs to the labouring caste groups and, thus, in supporting their livelihoods. There was clearly a conflation of historical representations of Jats (as landowners, as providers of work) and contemporary representations (as a proud group, as generous) in order to construct the caste ingroup in positive terms. There was a conflation of geographical contexts - both the Punjabi village and the diaspora - in promoting this positive representation. On the one hand, this representation associated Jats with competence and control and enhanced a positive self-conception on the basis of caste, bolstering self-efficacy and self-esteem, respectively.

Similarly, the Dalits who participated in this study expressed pride in their caste group membership. While the Jats tended to invoke traditional models of caste organisation, such as the division of labour, the Dalits rejected these criteria for evaluating caste:

I'm proud of my caste [dalit]. People just look at the conditions in India but if you go back in history you can see the important, I mean, the big role of Ravidassia in Sikhism, battles, even independence. It's something to be proud of. (Satpal, Dalit)

There was a rejection of social representations of Dalit poverty among Dalit respondents, who regarded this as a poor indicator of the value of their caste ingroup, unlike Jat interviewees who, conversely, pointed to their position of economic power in the Subcontinent. Satpal constructed the Ravidassia as occupying an important position in the history of Sikhism, that is, in the development and defence of the religion. Moreover, he argued that the Dalits had played a similarly important role in facilitating the independence of India in 1947. By anchoring his caste ingroup to these positive historical representations, Satpal constructed his caste group membership as "something to be proud of" in much the same way as other caste groups. This was clearly beneficial for both distinctiveness (as occupants of a unique position in history) and for self-esteem, since their caste identity was construed as something to be proud of.

In addition to drawing upon positive historical representations, respondents attributed positive traits and characteristics to their caste ingroup:

There's a lot of intelligent Sainis here in the [names a city in the Midlands], you can see, we 're really business minded and quite successful. It's only really Sainis who manage it (Karan, Saini)

In our caste you get a lot of really generous people, I think. There's more education and there's not a lot of, I don't like alcoholism [...] like you get in some castes, so we're different (Arpandeep, Saini)

Karan noted that in the Midlands city in which he resided there were many "intelligent Sainis" who were "successful" and "business minded", which served to imbue his caste group identity with positive value. Similarly, Arpandeep attributed the positive trait of generosity to his caste ingroup and noted that there was "more education" and not many cases of alcohol abuse within his caste group. These observations were largely anecdotal in nature but by making these attributions, individuals were able to construct their caste ingroup as worthy of pride and self-esteem, rather than as being in any way stigmatised. Interviewees were mindful 
of the positive and negative stereotypes surrounding their caste ingroups and, thus, their attributional tendencies enabled them to respond to these stereotypes in ways that were conducive to a positive sense of self. Karan was able to construct his caste ingroup as worthy of self-esteem, while Arpandeep clearly derived a sense of distinctiveness on the basis of her caste group membership.

Individuals often described characteristics of caste ingroup members within particular geographical locations, such as one's town of residence or the UK in general, which allowed them to dispel any negative stereotypes associated with their caste group within the Indian Subcontinent. This was a form of resistance to caste-based stigma (Jaspal, 2011). In the context of his hometown in the Midlands, it was reportedly "only really Sainis" who were successful and self-efficacious, not other caste groups. Interestingly, when caste identity was invoked in the interviews, individuals themselves used this as a social category/ division for discussing matters, such as success in business and affluence. While this enabled respondents to dispel negative (higher-level) stereotypes regarding one's caste group membership, interviewees were keen to highlight the positive general characteristics of their caste ingroup, frequently vis-à-vis caste outgroups:

I've not thought of any day to day differences but you can see that Sainis are basically similar to Jats but you know they maybe more sort of cultured and not getting absolutely off your trolley at weddings and that, but pretty similar. (Karanvir, Saini)

In support of the stereotype invoked by Arpandeep, Karanvir highlighted the (positive) distinctiveness of his Saini ingroup vis-à-vis the Jat outgroup. While he acknowledged some basic similarities between the caste groups, one key difference was the perception of alcohol abuse in the Jat outgroup and the "cultured" orientation of the caste ingroup. Both Amandeep and Karanvir contrasted their caste ingroup with outgroups on favourable dimensions in order to crystallise the notion that their caste ingroup was characterised by positive traits and, thus, worthy of self-esteem and positive distinctiveness. Indeed, social psychologists have described the phenomenon of downward comparison, whereby individuals seek to derive positive wellbeing in face of negative affect by comparing themselves to less fortunate others (Jaspal, 2011; Wills, 1981). Respondents did often recognise potentially unfavourable aspects of their caste ingroup identities but nevertheless highlighted their "superiority" to caste outgroups by emphasising favourable dimensions, such as their "cultured" orientation and abstinence from alcohol, as exemplified by Karanvir's account. This was important because for many respondents caste constituted an inherent aspect of identity, which was inextricably entwined with ethnicity, culture and religious heritage.

\section{Caste as an Inherent or Constructed Aspect of Identity?}

Although caste identity did not necessarily dominate the identity structure or affect interpersonal relations in everyday life, interviewees did recognise this as an important aspect of the self. Among Jat and Saini respondents, caste was essentialised as an inherent aspect of the self:

This is who I am, I guess. Just as I'm Indian, brown, a Sikh, a guy, I'm a Jat. It's not a big thing but it's still a part of who I am [...] You know, like my past. My background. And I am proud of my background. (Jas, Jat)

The way I see it is, even as a woman, if I go and get married to a Jat or a guy from another caste, my name changes but deep down I'm still a Saini and that stays the same [...] your caste is in your blood really. (Gurmeet, Saini) 
Both Jas and Gurmeet perceived their caste identity as a key aspect of who they were. Jas compared his caste identity to other identity aspects that tend to be essentialised, such as his ethnicity and gender. His caste identity was comparable to being "brown, a Sikh, a guy". Jas reiterated the lack of centrality that his caste identity had in his everyday life but nonetheless regarded it as "still a part of who I am". He appeared to derive a sense of continuity on the basis of his caste identity given that it reflected a connection between his past and present, and was a clear aspect of his "background". Similarly, Gurmeet perceived her Saini caste identity as immutable, that is, resistant to change even through marriage. It is noteworthy that in the patriarchal system of the Indian Subcontinent women are usually considered as inheriting the caste identities of their husbands. Yet, despite this change in the eyes of society, Gurmeet claimed that "deep down I'm still a Saini" and referred to caste as being "in your blood", highlighting the perceived essentialism of her caste identity.

The tendency for individuals of socially privileged caste groups, such as the Jat and Saini caste groups, to essentialise their caste identities may well be attributed to the social psychological capital that they derived from these identities, that is, its ability to provide feelings of self-esteem, distinctiveness and so on:

I suppose it does feel good, you know, to say you're a Jat, even though there's a lot of us, there's a certain sort of pride with it, you know what I mean? It's something to be proud of. So I like telling someone if they ask (Sukhi, Jat)

Like Sukhi, most Jat respondents perceived their caste identity as a consistent source of selfesteem because it was socially represented in positive terms and, thus, he readily disclosed his Jat caste identity in interactions with others. Human beings more readily manifest those identities that enhance the identity principles (Vignoles, 2011). Interestingly, other interviewees highlighted the self-esteem that they were able to derive from their caste identity in face of identity threat associated with other identity aspects or positions they occupied in society:

My family and that we're not that, you know, well off, but still we're Jats, that's something (Manjit, Jat)

Manjit viewed some aspects of her identity as unfavourable, such as her family's lack of affluence vis-à-vis other Sikh families. However, her Jat caste identity provided an alternative source of pride and self-esteem. Indeed, it has been argued that, for the historically privileged caste groups, this identity can function as a perpetual source of self-esteem which can buffer threats to identity associated with other identity aspects (Jaspal, 2011). Thus, there was a social psychological incentive for essentialising caste identity as an inherent identity aspect, which could compensate for identity threat arising from other spheres of life.

Conversely, Dalit respondents who reflected upon the stigma associated with their caste identity tended to view their identity as constructed, rather than inherent:

A caste can change, yeah, it's not like I have "chamar" written on my forehead. This is a man-made thing, basically [...] (Amanjit, Dalit)

Unlike Jat and Saini interviewees who generally essentialised their caste identity, Dalits perceived their caste identity as mutable and "man-made". There was a tendency for individuals to perceived this identity as socially constructed and mutable, rather than 
essentialist and resistant to change. However, in contexts in which their caste identity was perceived in positive terms, Dalit interviewees too essentialised their caste identity:

But research does show that we were the first ones in Punjab, really, so it makes us true Indians really because Jats and other castes are more like a mix of other tribes [...] they are outsiders (Amanjit, Dalit)

Respondents were encouraged to reflect upon the historical aspects of their caste ingroup, including both favourable and unfavourable aspects of their histories. When they reflected upon the positive (historical) aspects of their caste identity, respondents tended to essentialise this self-aspect by contributing to the "authenticity" of their Indian/ Sikh identities. While Jats and other historically privileged caste outgroups were perceived as being "a mix of other tribes" and "outsiders", Amanjit regarded the Dalit ingroup as "the first ones in Punjab" and, thus, more authentically Indian. In short, caste identity was essentialised as providing both authenticity, on the one hand, and distinctiveness from "outsiders", on the other. Interviewees perceived their caste identities as either inherent or constructed in accordance with the social and evaluative context in which discussions surrounding caste identities took place.

\section{CONCLUSIONS}

This small-scale qualitative study of young Sikhs in the Midlands cannot be easily generalised to the wider British South Asian population. However, it does provide some incipient insights into how young second- and third-generation Sikhs may think about their caste identity and relations with caste outgroups. On the whole, caste appears to function as a dormant social category, given that our respondents appended little importance to this category in their everyday lives. Few participants thought about their caste group memberships and, conversely, attributed greater importance to superordinate identities, such as their Indian ethnicity and/or Sikh religious identity. This was true of all three caste groups represented in this study. However, there were some contexts in which caste identities did acquire salience. Respondents acknowledged that the first-generation did appear to attach importance to caste in the context of interpersonal relations and, particularly, marriage (Ballard, 1994). It appears that caste endogamy remains an important underlying principle in the lives of at least some first-generation British South Asian Sikhs, because this constitutes a means of maintaining continuity of self-definition on the basis of caste. Because caste is an important symbolic aspect of identity, some Sikhs wish to maintain this identity through endogamy (Takhar 2005).

This can be partly explained through the lens of Identity Process Theory (Jaspal, 2011). Our interviewees clearly derived feelings of self-esteem, distinctiveness and continuity on the basis of their caste identities. While sometimes acknowledging the potential stigma associated with their caste groups, they resiliently emphasised those aspects of their caste identities that enhanced the identity principles, and deflected those threatening aspects of their caste group memberships. They (re-)constructed their caste group histories in ways that bolstered the identity principles and rejected those representations that challenged identity. Identities are often not fixed but are malleable and open to positive re-construal (Breakwell, 1986). Caste identity, though generally latent in the lives of our respondents, clearly performed positive functions for identity and, thus, it is unsurprising that caste is maintained as an important aspect of identity. Indeed, social psychologists acknowledge that those identity aspects that bolster the motivational principles of identity will be keenly maintained and manifested within the identity structure (Jaspal, 2011; Vignoles, 2011). Caste is no exception. In those contexts in which caste identity can provide feelings of self-esteem, distinctiveness and so on, it is likely to be essentialised as an inherent aspect of identity, 
while in less favourable social contexts it may be regarded as a socially constructed identity aspect that can change.

Human beings are motivated to identify with those identity aspects that inspire a sense of social and psychological wellbeing and, for our interviewees, caste (regardless of its location in the traditional hierarchy of the caste system) does inspire a positive sense of self. Interestingly, our interviewees generally reported no experiences of caste-based discrimination, either as victims or perpetrators, which raises questions about the frequency and extent of caste-based discrimination in Britain. However, there was an overarching perception that their caste ingroups were, in one way or another, distinctive and superior to caste outgroups. Jats, Sainis and Dalis all highlighted and accentuated those aspects of their caste ingroups that positioned them as "superior" to outgroups, which is consistent with the principle of downward comparison in social psychology (Wills, 1981). This universal grouplevel principle may easily be misunderstood as a principle that is unique to caste identity/ intergroup relations. This can render anti-caste legislation an attractive and even necessary step. However, many social groups - ethnic, religious, national, occupational, sexual and others - habitually engage in downward comparison, in order to ensure that their group membership continues to provide distinctiveness and self-esteem. Naturally, groups need to be feel different and good about themselves, and they achieve this at least partly through downward comparison with outgroups.

Given the historical backdrop against which the question of caste is often considered, particularly in the Indian Subcontinent, the downward comparison principle may be misunderstood as evidencing grave intergroup prejudice towards the historically less privileged caste groups. This article is intended to highlight the complexity of caste identity and relations in the diaspora context, in which both the historically privileged and less privileged caste groups seem to derive social and psychological capital from their caste identities, and engage in downward comparison in order to continue to derive such capital. Moreover, the article demonstrates that the implicit stigmatisation of caste identification (as opposed to caste-based discrimination, which is quite distinct from this) could have negative outcomes both for social and psychological wellbeing among those who wish to identify with a caste group and for caste intergroup relations more generally. Anti-caste legislation, quite ironically, could introduce and reify caste boundaries where they habitually do not exist, induce caste-based thinking in spheres of social life from which caste-based thinking is usually absent, and induce tensions between groups which have never been felt before. It is hoped that this article will stimulate further research into caste identities in the South Asian diaspora and further discussion of the necessity and effectiveness of anti-caste legislation in the diaspora.

\section{REFERENCES}

Ballard, R. (ed.) (1994). Desh Pardesh: The South Asian Experience in Britain. London: C. Hurst \& Co.

Breakwell, G. M. (1986). Coping with threatened identities. London: Methuen.

Chowdhry, P. (2004). Caste panchayats and the policing of marriage in Haryana: Enforcing kinship and territorial exogamy. Contributions to Indian Sociology, 38, 1-42.

Dhanda, M. (2009). Punjabi dalit youth: social dynamics of transitions in identity. Contemporary South Asia, 17(1), 47-64. 
Dumont, L. (1988). Homo Hierarchicus: The Caste System and its Implications (trans. Mark Sainsury, Louis Dumont and Basia Gulati). Delhi: Oxford University Press.

Gorringe, H. \& Rafanell, I. (2007). The embodiment of caste: oppression, protest and change. Sociology, 41(1), 97-114.

Gupta, D. (2004). Caste in Question: Identity or Hierarchy? Delhi: Sage.

Jaspal, R. (2011). Caste, social stigma and identity processes. Psychology and Developing Societies, 23(2) 27-62.

Jaspal, R. \& Breakwell, G.M. (eds.) (2014). Identity Process Theory: Identity, Social Action and Social Change. Cambridge: Cambridge University Press.

Jeffrey, C. (2001). 'A fist is stronger than five fingers': caste and dominance in rural north India. Transactions of the Institute of British Geographers, 26, 217-36.

Jodhka, S.S. (2004). Sikhism and the caste question: Dalits and their politics in contemporary Punjab. Contributions to Indian Sociology, 38, 165-91.

Judge, P.S. \& Bal, G. (2008). Understanding the paradox of changes among Dalits in Punjab. Economic and Political Weekly, October $11^{\text {th }}, 49-55$.

Kalsi, S.S. (1989). The Sikhs and caste: a study of the Sikh community in Leeds and Bradford. Unpublished doctoral dissertation, University of Leeds, UK.

Mahalingam, R. (2007) Beliefs about Chastity, Machismo, and Caste Identity: A Cultural Psychology of Gender. Sex Roles, 56, 239-249.

Nesbitt, E. (1994). Valmikis in Coventry: the revival and reconstruction of a community. In R. Ballard (ed.) Desh Pardesh. The South Asian Presence in Britain (pp. 117-41). London: Hurst and Co.

Pawar, I.D. (1993). My struggle in life. Chandigarh: Author Publisher.

Ram, Ronki "Ravidass Deras and Social Protest: Making Sense of Dalit Consciousness in Punjab (India).” The Journal of Asian Studies. 67 (2008): 1341-64.

Sato, K. (2012) Divisions among Sikh Communities in Britain and the Role of Caste System: A Case Study of Four Gurdwaras in Multi-Ethnic Leicester, Journal of Punjab Studies, 19(1), $1-26$.

Sharma, Neeru (2012) "Caste in Punjab: Political Marginalisation and Cultural Assertion of Scheduled Castes in Punjab”. Journal of Punjab Studies, 19 (1): 27 - 48.

Smith, J. A., \& Osborn, M. (2008). Interpretative phenomenological analysis. In J. A. Smith (Ed.), Qualitative psychology: A practical guide to methods (pp. 53-80). London, England: 
Sage.

Takhar, Opinderjit Kaur (2005) Sikh Identity: An exploration of groups among Sikhs.

Aldershot: Ashgate.

Takhar, Opinderjit Kaur (2011) "We are not Sikhs or Hindus: Issues of Identity among the Valmikis and Ravidasias in Britain" in Singh, Pashaura (ed ) Sikhism in Global Context. New Delhi: Oxford University Press.

Takhar, Opinderjit Kaur (2014) "The Place of Scripture in the Trajectories of a Distinct Religious Identity among Ravidassias in Britain: Guru Granth Sahib or Amritbani Guru Ravidass". Journal of Contemporary Religion, 29:1, 105-120.

Valmiki, Omprakash (2003) Joothan: An Untouchable's Life (Translated into English by Arun Mukherjee). New York: Columbia University Press.

Vignoles, V. L. (2011). Identity motives. In S. J. Schwartz, K. Luyckx and V. L. Vignoles (eds.), Handbook of identity theory and research (pp. 403-432). New York: Springer.

Wills, T. A. (1981). Downward comparison principles in social psychology. Psychological Bulletin, 90, 245-271

\section{Notes}

${ }^{1}$ This term is one that is preferred by members of the Scheduled Classes, it translates as one who is 'oppressed and crushed'. It is important to note that Dalits may also define themselves as Sikh or Hindu. However, there is a growing preference for Dalits to label themselves as the 'other' to Sikhs and Hindus (see Takhar 2014).

${ }^{2}$ See Neeru Sharma (2012) for an insight into the different castes amongst Sikhs.

${ }^{3}$ Available at http://www.britishsikhreport.org/british-sikh-report-download-2013

${ }^{4}$ Case studies of such discrimination can be found in the NIESR report "Caste discrimination andharassment in Great Britain" (December 2010), available at

https://www.gov.uk/government/uploads/system/uploads/attachment_data/file/85522/castediscrimination.pdf

${ }^{5}$ In terms of traditional occupations related to caste, the Jats define as farmers and hence the predominant landowning caste. Their economic stability during the Green Revolution has given the Jats Political dominance in the Punjab. The Sainis are also agriculturalists who trace their lineage to the Rajput Class. The traditional occupations of the two largest subcastes of the Dalit community are leather-working and cleaning. In terms of providing a hierarchical scale of castes in the Punjab, the Jats tend to occupy that of the historically privileged in the Punjab, whereas the Dalits continue to be perceived as the stigmatised - the very term Dalit is indicative of their position in rural Punjabi communities. The Sainis occupy a social position underneath the Jats in the hierarchical social scale of the Punjab. 